\title{
Could adolescents be the vehicle that transfers a no-smoking rule from school to home?
}

\author{
Dimitra Mpousiou ${ }^{1,2}$, Elpidoforos S. Soteriades ${ }^{2,3,4,5}$, Stavros Patrinos ${ }^{6}$, Nickolaos Sakkas ${ }^{7}$, Anna Karakatsani ${ }^{1,2,8}$, Areti \\ Karathanasi ${ }^{9}$, Chrstina Gratziou ${ }^{10}$, Paraskevi A. Katsaounou ${ }^{1,2,11}$
}

\begin{abstract}
INTRODUCTION Banning smoking at home, schools, children's playgrounds and indoor environments, constitutes an integral part of tobacco control efforts to prevent uptake of smoking among young teenagers. We aimed at exploring the role of teenagers as facilitators of change in enforcing a home no-smoking rule following school-based anti-tobacco programs and examining the effect of home no-smoking rule on teenagers' intention to smoke.
\end{abstract}

METHODS A school-based intervention-control study was implemented during the 2016-2017 academic year among middle-school students in Athens, Greece. The experiential learning intervention was delivered using an interdisciplinary approach, bridging excerpts from ancient classical Greek myths and ancient classical literature, with their decoded archetypal symbols applied in a smoking and tobacco control paradigm. An anonymous selfadministered questionnaire was used at baseline, and at follow-up at 3 months to evaluate program effectiveness. A chi-squared test was used for categorical variables and a t-test for continuous variables. Cohen's distance (d) was employed to examine the intervention effect size. A two-tailed $\mathrm{p} \leq 0.05$ was considered statistically significant using IBM SPSS V.22.

RESULTS In all, 351 students participated. At baseline, $47.5 \%$ in the intervention group reported a home no-smoking rule and $86 \%$ indicated being unlikely to smoke, these increased to $61.3 \%(\mathrm{p}=0.016)$ and $98.2 \%(\mathrm{p}<0.001)$ at followup, respectively. Cohen's d value was calculated to estimate the effect size of intervention. A large effect size of intervention was found in the intervention group $(\mathrm{d}=1.24)$, whilst $\mathrm{d}=0.19$ in the control group.

CONCLUSIONS Our study showed that our intervention led to the increase of no-smoking rules at home and to a negative intention towards smoking of adolescents. Consequently, we provide evidence that students are effective vehicles for carrying anti-smoking messages to their home environment including the no-smoking rule. Additionally, we confirmed previous reports that home no-smoking rule is associated with a negative intention to smoke and risk of smoking.

\section{AFFILIATION}

Medical School, National and Kapodistrian University of Athens, Athens, Greece

2 Hellenic Thoracic Society, Athens, Greece 3 Healthcare Management Program, School of Economics and Management, Open University of Cyprus, Nicosia, Cyprus 4 Institute of Public Health, College of Medicine and Health Sciences, United Arab Emirates University, Al Ain, United Arab Emirates

5 Environmental and Occupationa Medicine and Epidemiology Program, Department of Environmental Health, Harvard T. H. Chan School of Public Health, Boston, United States

6 National Public Health Organization, Athens, Greece

7 Department of Physiotherapy, School of Bioscience, Faculty of Life Sciences and Medicine, King's College London, London, United Kingdom

8 2nd Pulmonary Medicine Department, Medical School, National and Kapodistrian University of Athens, Attikon University General Hospital, Athens, Greece 9 Institute of Educational Policy, Ministry of Education and Religious Affairs, Athens, Greece

10 Evgenidion Clinic Agia Trias S. A., National and Kapodistrian University of Athens, Athens, Greece

11 First Intensive Care Unit, Department of Pulmonary Medicine, Evaggelismos General Hospital, Athens, Greece

\section{CORRESPONDENCE TO}

Paraskevi A. Katsaounou. Medical School, National and Kapodistrian University of Athens, Athens, Greece. Email: vkatsaounou@yahoo.com ORCID ID: https://orcid.org/0000-0002-8736-619X

\section{KEYWORDS}

smoke-free home, smoking prevention, teenagers, home exposure

Received: 7 December 2020

Revised: 12 May 2021

Accepted: 17 May 2021 


\section{INTRODUCTION}

Tobacco control programs span through a myriad of approaches, including relevant legislation, tobacco control policies, anti-tobacco population campaigns, school-based preventive programs, and smoking cessation services ${ }^{1}$. A smoking ban at home, schools, children's playgrounds and indoor environments in general constitutes an integral part of tobacco control efforts aiming to prevent the uptake of smoking among young teenagers ${ }^{2,3}$. While the change in beliefs and attitudes about smoking among teenagers imposes complex challenges, home no-smoking rules represent a relatively simple and practical approach for smoking prevention ${ }^{4}$. Specifically, this rule has been shown to lower the risk of smoking initiation among adolescents, even if their friends ${ }^{5}$ or both parents are smokers ${ }^{3,6}$. Furthermore, it empowers tobacco control attitudes and lowers teenagers' perceived prevalence of smoking ${ }^{7}$. In addition, it eliminates images of role models of smoking at home $^{8}$, and increases the intention to quit smoking among family members leading to successful smoking cessation ${ }^{9}$, and overall decreased risk of adolescent smoking ${ }^{10-12}$. Lastly, a home no-smoking rule protects children from secondhand and thirdhand smoke ${ }^{2,13}$, and may also serve as a non-smoking norm at home even if parents are smokers ${ }^{14}$.

In contrast, smoking at home facilitates the exposure of teenagers to smoking behavior and negative parental role modeling and has been associated with positive beliefs, attitudes and expectations towards tobacco. In addition, it leads to a higher intention to smoke as well as a higher probability of smoking among teenagers ${ }^{15-18}$. Furthermore, it facilitates access to cigarettes and other tobacco products, while it undermines the value of role modeling of non-smoking parents or other adult household members ${ }^{19,20}$.

While the above-cited studies have shown an association of the home no-smoking rule with different aspects of adolescent smoking, there is little in the international literature on whether teenagers may also serve as vehicles of change at home using a bottom-up approach. Therefore, our study aimed to improve adolescents' knowledge so that they can act as facilitators of change in enforcing the home nosmoking rule following school-based anti-tobacco programs.

\section{METHODS}

The study was implemented during the 2016-2017 academic year among middle-school students in Athens, Greece, under permission from the Greek Ministry of Education and approval from the Bioethics Committee of Evangelismos Hospital (16/6/2016, Protocol number 131), an affiliated hospital of the National and Kapodistrian University, Medical School. The study was implemented in five middle schools. Students from 1st to 3rd middle-school grade were invited to participate in either in the intervention or control group. Written informed consent was signed by students' parents who participated in the study.

The intervention used an experiential learning approach that included the reading of an excerpt from the Histories Book 5: Terpsichore [Herodotus' Histories (5.92) ${ }^{21}$. This is a parable from the story of the tyrant of Corinth, Periandros, who was wondering how to protect his power and was told that the best way was to destroy the strong sheaves of the field, representing the most accomplished members of the society. Using this parable, adolescents were paralleled with the strongest sheaves, which have the potential to become the modifiers of society and play an active role in shaping a healthier community away from substance abuse and addiction. This was followed by a class discussion of its meaning through a focused retrieval and decoding of archetypal symbols, as reflected and applied in real-life scenarios, including tobacco control messages. After the intervention, students participated in role-playing and encouraged to declare their contribution as the strong sheaves of the community. As a follow-up activity, students were guided to write a letter to their parents to motivate them to implement the no-smoking rule at home.

Our intervention occurred in school classrooms of 20-25 students during their everyday program and lasted for two school hours plus the in-between break. Students from both groups completed anonymous self-administered questionnaires twice (before and after the intervention). Data collection lasted for about seven months (academic year 20162017) at five public schools in the northwestern suburbs of Athens. To avoid performance bias, the experiential learning intervention was carried out by the same investigator in all class sessions. The 
home no-smoking rule was documented by students' reports at baseline and at the follow-up at 3 months using the following multiple-choice item: 'What rules are applied at your home related to smoking?'. Responses included: 1) No one is allowed to smoke inside the house, 2) Smoking at home is allowed only for guests, and 3) Smoking is freely allowed for everyone. A pre- and post-intervention item was also used to evaluate students' intention to smoke regarding their likelihood of taking up smoking in the future (12 months) following the intervention.

Data were entered into a computerized database and analyzed using the statistical package for social sciences (IBM SPSS v 22). Associations were assessed between a home no-smoking rule and the intention to smoke among students in the intervention and control groups at baseline and at the follow-up at 3 months.

Chi-squared tests were used for categorical variables and t-tests for continuous variables. To discretely assess students' knowledge, attitudes and intention toward smoking, a total score was calculated for each outcome. For corresponding questions: positive answers were tabulated as 1 , negative answers as -1 , and neutral answers as 0 . The score of the knowledge and attitudes scale takes values from -16 (incomplete knowledge and attitudes) to +16 (full knowledge and attitudes). Attitudes scores ranged from -9 to +9 , respectively. A two-tailed p-value of $\leq 0.05$ was considered statistically significant.

\section{RESULTS}

A total of 351 students participated in our study, with $181(51.6 \%)$ in the intervention group and 170 $(48.4 \%)$ in the control group. The mean age of student participants was $13.00 \pm 0.96$ years; $12.76 \pm 0.91$ years in the intervention and $13.26 \pm 0.95$ years in the control group $(\mathrm{p}<0.001)$. The majority of participants were female $(191 ; 54.5 \%)$, and the distribution of middleschool students across grades was $202(57.5 \%)$ in Grade 1, 68 (19.4\%) in Grade 2, and 81 (23.1\%) in Grade 3. There was a significant difference in age distribution between the intervention and control groups.

In the intervention group, $80.7 \%$ of students before the intervention and $94.5 \%(\mathrm{p}<0.001)$ after the intervention replied that they believe they will not smoke in the future (Table 1). There was no impact of gender between the intervention and control group $(p=0.335)$ and the gender ratio was very close to $1: 1$. Within males, the belief that they will not smoke increased (75.9\% pre vs $91.9 \%$ post, $\mathrm{p}=0.015)$. In females, similar results emerged ( $85.1 \%$ pre vs $96.8 \%$ post, $\mathrm{p}=0.017$ ).

In the intervention group, reporting that no one is allowed to smoke at home increased after the intervention ( $47.5 \%$ vs $61.3 \%, \mathrm{p}=0.016)$, whilst in the control group, no significant change was noticed ( $51.8 \%$ vs $50 \%, \mathrm{p}=0.922$ ) (Table 2 ). Reporting

\section{Table 1. Intention to smoke}

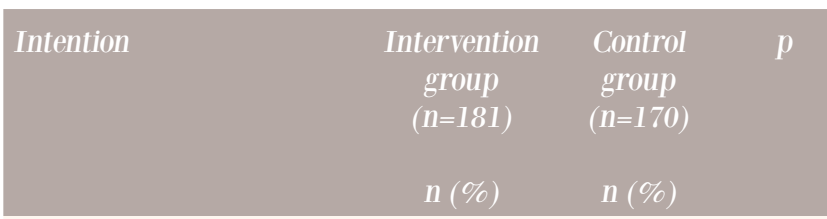

I will smoke in the future

0.764

(Before intervention)

Not possible

Possible

$\begin{array}{cc}146(80.66) & 140(82.35) \\ 30(16.57) & 24(14.12) \\ 5(2.76) & 6(3.53)\end{array}$

Very possible

I will smoke in the future

(After intervention)

Not possible

$\begin{array}{cc}171(94.48) & 128(75.29) \\ 9(4.97) & 35(20.59) \\ 1(0.55) & 7(4.12)\end{array}$

Very possible

$1(0.55)$

Males

87 (48.07) 73 (42.94)

Females

94 (51.93) $97(57.06)$

I will smoke in the future Before After 0.015

(Intervention group: $n=174$ intervention intervention males)

Not possible

66 (75.86) $\quad 80$ (91.95)

Possible

18 (20.69) $\quad 6(6.90)$

Very possible

$3(3.45)$

1 (1.15)

I will smoke in the future

(Intervention group $\mathrm{n}=188$

Before

After

0.017 females)

Not possible

80 (85.11) 91 (96.81)

Possible

$12(12.77) \quad 3(3.19)$

Very possible

2 (2.13)

$0(0.00)$

I will smoke in the future Before After $<0.001$

(Intervention group $n=362$ ) intervention intervention

Not possible

146 (80.66) 171 (94.48)

Possible

$30(16.57) \quad 9(4.97)$

Very possible

$<0.001$

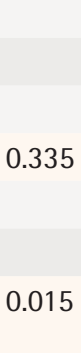

0.017


that both parents do not smoke did not statistically change in either the intervention group (48.1\% pre vs $42.5 \%$ post, $\mathrm{p}=0.291$ ) or in the control group ( $50 \%$ vs $53.5 \%, \mathrm{p}=0.515)$. In the intervention group, the existence of a no-smoking ban was statistically significantly associated with the intention to smoke among teenagers $(\mathrm{p}<0.001)$ both before and after the intervention (Table 2). The intention to smoke in the next 12 months and parental non-smoking status were neither associated before $(p=0.053)$ nor after

Table 2. Association between the no-smoking rule at home and the intention to smoke

\begin{tabular}{|c|c|c|c|c|}
\hline & $\begin{array}{c}\text { No one allowed to } \\
\text { smoke at home } \\
n(\%)\end{array}$ & $\begin{array}{l}\text { Only visitors allowed } \\
\qquad n(\%)\end{array}$ & $\begin{array}{l}\text { Allowed } \\
n(\%)\end{array}$ & $p$ \\
\hline \multicolumn{5}{|l|}{ Home no-smoking rule ${ }^{* *}$} \\
\hline Intervention group & & & & 0.016 \\
\hline Before intervention & $86(47.5)$ & $39(21.5)$ & $56(30.9)$ & \\
\hline After intervention & $111(61.3)$ & $35(19.3)$ & $35(19.3)$ & \\
\hline Control group & & & & 0.922 \\
\hline Before intervention & $88(51.8)$ & 39 (22.9) & $43(25.3)$ & \\
\hline After intervention & $85(50.0)$ & $42(24.7)$ & $43(25.3)$ & \\
\hline Parents smoking & Both parents smoke & Parents do not smoke & & \\
\hline Intervention group & & & & 0.291 \\
\hline Before intervention & $94(51.9)$ & $87(48.1)$ & & \\
\hline After intervention & $104(57.5)$ & $77(42.5)$ & & \\
\hline Control group & & & & 0.515 \\
\hline Before intervention & $85(50.0)$ & $85(50.0)$ & & \\
\hline After intervention & $79(46.5)$ & $91(53.5)$ & & \\
\hline $\begin{array}{l}\text { Home no-smoking rule and intention } \\
\text { to smoke* }\end{array}$ & $\begin{array}{l}\text { No one allowed to } \\
\text { smoke at home }\end{array}$ & Only visitors allowed & Allowed & \\
\hline \multicolumn{5}{|l|}{ Intervention group } \\
\hline Will not smoke in the future & $74(86.0)$ & $36(92.3)$ & $37(66.1)$ & \multirow{3}{*}{$\begin{array}{l}\text { Before intervention } \\
\quad \mathrm{p}<0.001\end{array}$} \\
\hline Possible to smoke in the future & $12(14.0)$ & $3(7.7)$ & $15(26.8)$ & \\
\hline Very possible to smoke in the future & $0(0.0)$ & $0(0.0)$ & $4(7.1)$ & \\
\hline Will not smoke in the future & 109 (98.2) & $30(85.7)$ & $32(91.4)$ & \multirow{3}{*}{$\begin{array}{l}\text { After intervention } \\
\quad \mathrm{p}<0.001\end{array}$} \\
\hline Possible to smoke in the future & $2(1.8)$ & $4(11.4)$ & $3(8.6)$ & \\
\hline Very possible to smoke in the future & $0(0.0)$ & $1(2.9)$ & $0(0.0)$ & \\
\hline \multicolumn{5}{|l|}{ Control group } \\
\hline Will not smoke in the future & 82 (93.2) & $28(71.8)$ & $30(69.8)$ & \multirow{3}{*}{$\begin{array}{l}\text { Before intervention } \\
\quad \mathrm{p}<0.001\end{array}$} \\
\hline Possible to smoke in the future & $5(5.7)$ & $8(20.5)$ & $10(23.3)$ & \\
\hline Very possible to smoke in the future & $1(1.1)$ & $3(7.7)$ & $3(7.0)$ & \\
\hline Will not smoke in the future & $77(90.6)$ & $27(64.3)$ & $24(55.8)$ & \multirow{3}{*}{$\begin{array}{l}\text { After intervention } \\
\quad p<0.001\end{array}$} \\
\hline Possible to smoke in the future & $7(8.2)$ & $12(28.6)$ & $16(37.2)$ & \\
\hline Very possible to smoke in the future & $1(1.2)$ & $3(7.1)$ & $3(7.0)$ & \\
\hline $\begin{array}{l}\text { Parents smoking and intention to } \\
\text { smoke }\end{array}$ & Both parents smoke & $\begin{array}{l}\text { Both parents do not } \\
\text { smoke }\end{array}$ & & \multirow{4}{*}{$\begin{array}{l}\text { Before intervention } \\
\qquad p=0.053\end{array}$} \\
\hline \multicolumn{5}{|l|}{ Intervention group } \\
\hline Will not smoke in the future & $70(47.6)$ & $77(52.4)$ & & \\
\hline Possible to smoke in the future & $21(70.0)$ & $9(30.0)$ & & \\
\hline Very possible to smoke in the future & $3(75.0)$ & $1(25.0)$ & & \\
\hline \multicolumn{5}{|l|}{ Control group } \\
\hline Will not smoke in the future & $98(57.3)$ & $73(42.7)$ & & \multirow{3}{*}{$\begin{array}{l}\text { After intervention } \\
\qquad p=0.435\end{array}$} \\
\hline Possible to smoke in the future & $6(66.7)$ & $3(33.3)$ & & \\
\hline Very possible to smoke in the future & $0(0.0)$ & $1(100.0)$ & & \\
\hline
\end{tabular}

*Adolescents' intention to smoke in the future (following 12 months); their belief/prediction about the likelihood of themselves to smoke in the following 12 months. ${ }^{* *}$ No smoking rule at home; smoking is not allowed at home as a family rule. 
the intervention ( $\mathrm{p}=0.435)$ (Table 2$)$.

We observed a statistically significant improvement in knowledge acquisition in the intervention group, which was not seen in the control group. Overall, the mean knowledge score was increased by 1.24 standard deviations in the intervention group and by 0.19 standard deviations in the control group, which indicates that the intervention is effective in the improvement of knowledge that leads to the enhancement of the no-smoking rule at home. Further, we observed an increase in non-smoking intention in the intervention group, as students reported that they were unlikely to smoke in the 12 months following the intervention.

\section{DISCUSSION}

We found that the observance of the home nosmoking rule was associated with students' lower intention to smoke in the future, in agreement with the literature, which documents that environments free from tobacco smoke protect students from exposure to secondhand smoke $e^{8,13,22}$ and from the uptake of smoking behavior ${ }^{3,6,12,15}$. Furthermore, our school-based intervention contributed to the diffusion of tobacco control messages to students' parents and to a higher percentage of enforcement of the home no-smoking rule.

The relevant literature shows that parents' smoking behavior has a significant effect on children smoking choices. Children may also exert a positive impact on parents' attitudes and behavior as well as influence community norms and serve as vehicles of change ${ }^{23}$. Genuine open discussions between parents and their children regarding smoking behavior may also have positive outcomes in preventing teenagers' smoking initiation ${ }^{24}$.

Experiential learning programs at schools appear effective in engaging students in active participation. In addition, the combination of experiential learning with multidisciplinary approaches using ancient Greek literature, applied in our program, provided students with the opportunity to deviate from the passive role of listener and engage in active participation, developing creative and critical thinking, and providing a level platform for all students to be involved irrespective of their academic performance $\mathrm{e}^{25-27}$.

Our study provided evidence that adolescents could act as vehicles of non-smoking messages from school to home. Therefore, our findings could encourage students and children to undertake active roles in educational and community settings to diffuse public health messages in general and tobacco control messages in the home, with family and in community environments.

\section{Strengths and limitations}

The strengths of our study are that we used a simple, solid, clear home no-smoking rule as an easily implemented guideline, which has a significant and multi-level effect on adolescents' and adults' smoking. We also used an experiential learning method that is a successful approach for engaging students without triggering resistance to transfer knowledge and skills related to tobacco control messages at home, where an innovative component, classic texts of the ancient Greek literature, was added.

The limitations of our study include the use of a convenience student sample and a self-reported questionnaire that may lead to socially acceptable responses. However, although the student participants were enrolled from five schools in the northwest region of Athens based mainly on the collaboration of school directors, we believe that the selected student population may be relatively representative of the students attending public schools in Athens because the student population of the public education system is more or less homogeneous with respect to socioeconomic status and school performance, as research has indicated that socioeconomic status can mediate adolescents' SHS exposure ${ }^{28}$. Additionally, most of the literature concerning adolescents' smoking refers to the use self-reported questionnaires and not biochemical markers, as smoking in adolescence is usually occasional. Moreover, the effectiveness of the intervention was evaluated only at the follow-up at 3 months, however, peer reviewed literature supports that short-term positive finding are usually persistent over longer periods ${ }^{29}$. Data collection was available from students who were present on the day of intervention and at follow-up. In accordance with wider literature, absent students tend to demonstrate lower academic achievement and appear more susceptible to addictive behaviours ${ }^{30,31}$. However, potentially high-risk students were not 
differentially absent from one of the two comparison groups. Finally, students who did not participate may introduce selection bias since they may originate from households with lower awareness about smoking $^{32}$. Nevertheless, in our study, the proportion of student smokers was similar in both groups.

\section{CONCLUSIONS}

The findings of our study support that our experiential learning program was successful in improving adolescent students' knowledge about smoking. It also re-confirmed that the home no-smoking rule had a measurable and significant effect on a negative intention to smoke among adolescents. Children from a home with indoor smoking restrictions were less likely to express an intention to smoke in the next 12 months. In addition, we documented that students from the intervention group were effective facilitators of tobacco control messages to their home environment, thereby increasing the percentage of home no-smoking rules enforced at follow-up. This is an important finding, showing that students may also be successful transmitters of anti-smoking messages and may have a loud voice on such matters. Increasing the prevalence of home no-smoking rule leads to several advantages including the decrease of secondand third-hand smoke exposure and associated risks for adolescents and adults, decreased risk of smoking uptake from adolescents, and propagation of such rules in homes of students who will become adults and future parents.

\section{REFERENCES}

1. Centers for Disease Control and Prevention. Best Practices for Comprehensive Tobacco Control Programs - 2014. Department of Health and Human Services, Centers for Disease Control and Prevention, National Center for Chronic Disease Prevention and Health Promotion, Office on Smoking and Health; 2014. Accessed December 2020. https://www.cdc.gov/tobacco/stateandcommunity/ best_practices/pdfs/2014/comprehensive.pdf

2. Ling MYJ, Lim KH, Hasani WSR, et al. Exposure to secondhand smoke among school-going adolescents in Malaysia: Findings from the tobacco and e-cigarettes survey among Malaysian adolescents (TECMA). Tob Induc Dis. 2020;18(November):1-11. doi:10.18332/tid/128622

3. Rainio SU, Rimpelä AH. Home smoking bans in Finland and the association with child smoking. Eur J Public Health. 2008;18(3):306-311. doi:10.1093/eurpub/ckm098

4. Kennedy C, Kennedy J. Teacher Attitudes and Change
Implementation. System. 1996;24(3):351-360. doi:10.1016/0346-251X(96)00027-9

5. Szabo E, White V, Hayman J. Can home smoking restrictions influence adolescents' smoking behaviors if their parents and friends smoke? Addict Behav. 2006;31(12):22982303. doi:10.1016/j.addbeh.2006.02.025

6. Andersen MR, Leroux BG, Bricker JB, Rajan KB, Peterson AV. Antismoking parenting practices are associated with reduced rates of adolescent smoking. Arch Pediatr Adolesc Med. 2004;158(4):348-352. doi:10.1001/archpedi.158.4.348

7. Albers AB, Biener L, Siegel M, Cheng DM, Rigotti N. Household Smoking Bans and Adolescent Antismoking Attitudes and Smoking Initiation: Findings From a Longitudinal Study of a Massachusetts Youth Cohort. Am J Public Health. 2008;98(10):1886-1893. doi:10.2105/AJPH.2007.129320

8. Evans-Whipp TJ, Bond L, Ukoumunne OC, Toumbourou JW, Catalano RF. The impact of school tobacco policies on student smoking in Washington State, United States and Victoria, Australia. Int J Environ Res Public Health. 2010;7(3):698-710. doi:10.3390/ijerph7030698

9. Gilpin EA, White MM, Farkas AJ, Pierce JP. Home smoking restrictions: which smokers have them and how they are associated with smoking behavior. Nicotine Tob Res. 1999;1(2):153-162. doi:10.1080/14622299050011261

10. Clark PI, Schooley MW, Pierce B, Schulman J, Hartman AM, Schmitt CL. Impact of home smoking rules on smoking patterns among adolescents and young adults. Prev Chronic Dis. 2006;3(2):A41. doi:10.5888/pcd12.140553

11. Kang H, Cho SI. Individual and joint association of adulthood experiences and parental or teacher smoking with adolescent cigarette smoking. Tob Induc Dis. 2020;18(October):1-11. doi:10.18332/tid/127519

12. Hiemstra M, de Leeuw RN, Engels RC, Otten R. What parents can do to keep their children from smoking: A systematicreview on smoking-specific parenting strategies and smoking onset. Addict Behav. 2017;70:107-128. doi:10.1016/j.addbeh.2017.02.003

13. Biener L, Cullen D, Di ZX, Hammond SK. Household smoking restrictions and adolescents' exposure to environmental tobacco smoke. Prev Med. 1997;26(3):358363. doi:10.1006/pmed.1997.0152

14. Conley Thomson C, Siegel M, Winickoff J, Biener L, Rigotti NA. Household Smoking Bans and Adolescents' Perceived Prevalence of Smoking and Social Acceptability of Smoking. Prev Med. 2005;41(2):349-356. doi:10.1016/j.ypmed.2004.12.003

15. Choi WS, Pierce JP, Gilpin EA, Farkas AJ, Berry CC. Which adolescent experimenters progress to established smoking in the United States. Am J Prev Med. 1997;13(5):385391. doi:10.1016/S0749-3797(18)30159-4

16. Freedman KS, Nelson NM, Feldman LL. Smoking Initiation Among Young Adults in the United States and 
Canada, 1998-2010: A Systematic Review. Prev Chronic Dis. 2012;9:110037. doi:10.5888/pcd9.110037

17. Rodriguez D, Romer D, Audrain-McGovern J. Beliefs about the risks of smoking mediate the relationship between exposure to smoking and smoking. Psychosom Med. 2007;69(1):106-113. doi:10.1097/PSY.0b013e31802e0f0e

18. Sargent JD, DiFranza JR. Tobacco control for clinicians who treat adolescents. CA Cancer J Clin. 2003;53(2):102123. doi:10.3322/canjclin.53.2.102

19. Forster J, Chen V, Blaine T, Perry C, Toomey T. Social exchange of cigarettes by youth. Tob Control. 2003;12(2):148-154. doi:10.1136/tc.12.2.148

20. Emory K, Saquib N, Gilpin EA, Pierce JP. The association between home smoking restrictions and youth smoking behaviour: a review. Tob Control. 2010;19(6):495-506. doi:10.1136/tc.2010.035998

21. Herodotus. The Histories Book 5: Terpsichore. National Geographic Society; 2017:310-311.

22. Nilsson R. Environmental tobacco smoke revisited: the reliability of the data used for risk assessment. Risk Anal. 2001;21(4):737-760. doi:10.1111/0272-4332.214147

23. Ballantyne R, Packer J. Promoting environmentally sustainable attitudes and behaviour through freechoice learning experiences: what is the state of the game? Environ Educ Res. 2005;11(3):281-295. doi:10.1080/13504620500081145

24. Harakeh Z, Scholte RH, de Vries H, Engels RC. Parental rules and communication: their association with adolescent smoking. Addiction. 2005;100(6):862-870. doi:10.1111/j.1360-0443.2005.01067.x

25. Chiu PHP, Cheng SH. Effects of active learning classrooms on student learning: a two-year empirical investigation on student perceptions and academic performance. Higher Education Research \& Development. 2017;36(2):269279. doi:10.1080/07294360.2016.1196475

26. Bonwell CC, Eison JA. Active Learning: Creating Excitement in the Classroom. The George Washington University, School of Education and Human Development; 1991. ASHE-ERIC Higher Education Report No. 1. 1991. Accessed May 12, 2021. https://files.eric.ed.gov/fulltext/ ED336049.pdf

27. Chatterjee N, Patil D, Kadam R. Testing the effectiveness of a teacher-training intervention to make schools tobacco-free in India: Results from a quasi-experimental post-only study. Popul Med. 2020;2(September):1-10. doi:10.18332/popmed/125912

28. Ziyab AH, Almari M, Al-Taiar A. Exposure to household secondhand smoke among adolescents in Kuwait: Results from two school-based cross-sectional studies. Tob Induc Dis. 2020;18(April):1-8. doi:10.18332/tid/119116

29. Hwang MS, Yeagley KL, Petosa R. A Meta-Analysis of Adolescent Psychosocial Smoking Prevention Programs Published Between 1978 and 1997 in the United States. Health Educ Behav. 2004;31(6):702-719. doi:10.1177/1090198104263361
30. Griffin KW, Botvin GJ. Evidence-Based Interventions for Preventing Substance Use Disorders in Adolescents. Child Adolesc Psychiatr Clin N Am. 2010;19(3):505-526. doi:10.1016/j.chc.2010.03.005

31. Reimers TM, Pomrehn PR, Becker SL, Lauer RM. Risk factors for adolescent cigarette smoking. The Muscatine study. Am J Dis Child. 1990;144(11):1265-1272. doi:10.1001/archpedi.1990.02150350097035

32. Pirie PL, Murray DM, Luepker RV. Smoking Prevalence in a Cohort of Adolescents, Including Absentees, Dropouts, and Transfers. Am J Public Health. 1988;78(2):176-178. doi:10.2105/ajph.78.2.176

CONFLICTS OF INTEREST

The authors have completed and submitted the ICMJE Form for Disclosure of Potential Conflicts of Interest and none was reported.

\section{FUNDING}

There was no source of funding for this research.

\section{ETHICAL APPROVAL AND INFORMED CONSENT}

The study was implemented under permission from the Greek Ministry of Education and approval from the Bioethics Committee of Evangelismos Hospital (16/6/2016, Protocol number 131), an affiliated hospital of the National and Kapodistrian University, Medical School. Written informed consent was signed by students' parents.

\section{DATA AVAILABILITY}

The data supporting this research is available from the authors on reasonable request.

\section{PROVENANCE AND PEER REVIEW}

Not commissioned; externally peer reviewed. 